\title{
A Development of the Epistemological Attitude towards Sources of Knowledge Questionnaire
}

\author{
Jevgenija Sivoronova and Aleksejs Vorobjovs \\ Daugavpils University, Latvia
}

\begin{abstract}
The research aims to develop the epistemological attitude towards sources of knowledge questionnaire and evaluate its content validity. The authors developed the model of epistemological attitude, a socio-psychological theory of cognition of sources of knowledge and their content. The theoretical foundations of the model are epistemological theories of cognition, philosophical and psychological aspects of personality cognition, social contexts of scientific and non-scientific cognition. The authors suppose cognition as a process occurring in three spheres, which is reflected in four dimensions of the epistemological attitude model. These dimensions are described as epistemological sphere's dimensions - epistemological approach and epistemological strategy, subjective sphere's dimension - activity principle of personality in cognition, and contextual sphere's dimension - cognition context. Based on the sixteen factors determining the content of the four structure model, a new instrument is developed to assess the use and significance of different sources of knowledge among students. In order to evaluate the degree to which the instrument has an appropriate sample of items for the epistemological attitude model, expert reviewers, the academics, university lecturers and professors, as subject matter experts connected to philosophy, psychology, methodology and education, participated in this study. Experts evaluated the content validity of the items $(\mathrm{k}=193)$ using the expert method, and the content validity index of the scale items was calculated. The experts' ratings confirmed the content validity of the instrument. Moderate inconsistencies in ratings across the experts were found and experiencing failures that reveal data quality problems are discussed.
\end{abstract}

Keywords: content validity index; epistemological attitude model; expert method; methodology; university academic staff 